\title{
Photoinduced Electron Transfer and Hole Migration in Nanosized Helical Aromatic Oligoamide Foldamers
}

\author{
Xuesong Li, ${ }^{\dagger, \ddagger}$ Nagula Markandeya, ${ }^{\dagger, \ddagger, \#}$ Gediminas Jonusauskas, ${ }^{\S}$ Nathan D. McClenaghan, \\ Victor Maurizot, ${ }^{\ddagger}$ Sergey A. Denisov, ${ }^{*}, \|$ and Ivan Huc*, \\ ${ }^{\dagger}$ Univ. de Bordeaux, CBMN (UMR 5248), Institut Européen de Chimie et Biologie, 2 rue Robert Escarpit, 33600 Pessac, France \\ ${ }^{\ddagger}$ CNRS, CBMN (UMR 5248), Institut Européen de Chimie et Biologie, 2 rue Robert Escarpit, 33600 Pessac, France \\ ${ }^{\S}$ Univ. de Bordeaux, Laboratoire Ondes et Matières d'Aquitaine (UMR5798), 351 cours de la Libération, 33405 Talence cedex, \\ France \\ "Univ. de Bordeaux, Institut des Sciences Moléculaires (UMR5255), 351 cours de la Libération, 33405 Talence cedex, France
}

\begin{abstract}
A series of photoactive triads have been synthesized and investigated in order to elucidate photoinduced electron transfer and hole migration mechanism across nanosized, rigid helical foldamers. The triads are comprised of a central helical oligoamide foldamer bridge with 9, 14, 18, 19, or 348 amino 2 quinolinecarboxylic acid repeat units, and of two chromophores, an $\mathrm{N}$ terminal oligo(para phenylenevinylene) electron donor and a $\mathrm{C}$ terminal perylene bis

imide electron acceptor. Time resolved fluorescence and transient absorption spectroscopic studies showed that, following photo

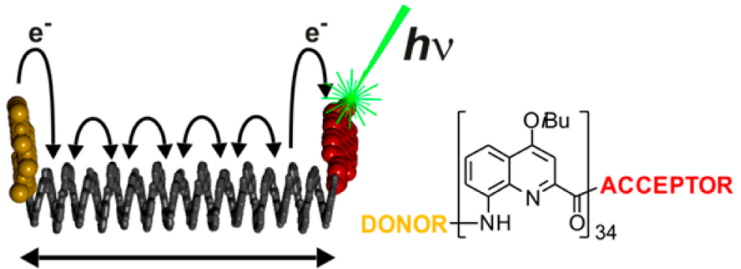

$5.1 \mathrm{~nm}$ excitation of the electron acceptor, fast electron transfer occurs initially from the oligoquinoline bridge to the acceptor chromophore on the picosecond time scale. The oligo(para phenylenevinylene) electron donor is oxidized after a time delay during which the hole migrates across the foldamer from the acceptor to the donor. The charge separated state that is finally generated was found to be remarkably long lived $(>80 \mu \mathrm{s})$. While the initial charge injection rate is largely invariant for all foldamer lengths (ca. $60 \mathrm{ps}$ ), the subsequent hole transfer to the donor varies from $1 \times 10^{9} \mathrm{~s}^{-1}$ for the longest sequence to $17 \times$ $10^{9} \mathrm{~s}^{-1}$ for the shortest. In all cases, charge transfer is very fast considering the foldamer length. Detailed analysis of the process in different media and at varying temperatures is consistent with a hopping mechanism of hole transport through the foldamer helix, with individual hops occurring on the subpicosecond time scale $\left(k_{\mathrm{ET}}=2.5 \times 10^{12} \mathrm{~s}^{-1}\right.$ in $\left.\mathrm{CH}_{2} \mathrm{Cl}_{2}\right)$. This work demonstrates the possibility of fast long range hole transfer over $300 \AA$ (through bonds) across a synthetic modular bridge, an achievement that had been previously observed principally with DNA structures.
\end{abstract}

\section{INTRODUCTION}

Electron transport through nucleic acids and proteins is central to a range of essential biomolecular processes, including photosynthesis, $^{1,2}$ enzyme catalysis ${ }^{3-5}$ and DNA repair. ${ }^{6-9}$ It can proceed between chromophores or other redox active chemical functions located at precise positions in space as a result of folding of the biopolymer backbones. These chromophores or redox centers may be in direct contact or, on the contrary, separated by long (nanometric) distances, in which case electron transport will greatly depend on the way charges may transfer between functionalities. In order to elucidate which parameters are critical to these biological functions, and with the perspective to engineer related bioinspired artificial molecular devices, chemists have produced a variety of small and well defined model molecular systems that are more amenable to study than biomacromolecules. For photoinduced charge transfer investigations, typical architec tures are composed of electron donor and electron acceptor units located at the termini of, often rigid, oligomeric bridges. The oligomeric bridges can be of various types, for example based on phenylenes, ${ }^{10-15}$ porphyrins, ${ }^{16}$ thiophenes, ${ }^{17}$ fluo renone and $p$ phenylethynylene ${ }^{18,19}$ as well as organometallic molecular wires. ${ }^{12,17,20-22}$ These systems typically allow one to assess the effect of distance between donor and acceptor, as well as the chemical composition of the bridge, on charge separation and charge recombination rates.

Aside from rigid bridges, more flexible structures but with an ability to adopt stable folded conformations, have been used to control the relative positioning of donor and acceptor units, and even of multiple chromophores. Examples include the use of peptides $^{23-29}$ and nucleotides ${ }^{23,30-41}$ and, in recent years, of non natural backbones, i.e., foldamers. ${ }^{42-46}$ Folding gives access to diverse and well defined relative orientations, the most common being the cofacial orientation of stacked aromatic chromophores. More specifically aromatic amide foldamers ${ }^{47,48}$ have emerged as a new class of tools for the fabrication of well defined, organic compatible, molecular and 
supramolecular nanometric architectures with atomic precision including sheets, ${ }^{49}$ multistranded helices, ${ }^{50,51}$ multihelical structures $^{52,53}$ and host-guest receptor systems ${ }^{54}$ the size of which may even match the size of small proteins. The investigation of electron transport within these objects thus bears relevance to their potential incorporation into devices, including sensors.

Along this line, we previously reported the photoinduced electron transfer between a perylene bis imide (PB) acceptor and an oligophenylene vinylene (OPV) donor separated by a foldamer bridge consisting of a helically folded oligoamide of 8 amino 2 quinolinecarboxylic acid (Q) comprised of 2, 4, 5, or 9 monomers (see molecular structures in Figure 1). ${ }^{55}$ These
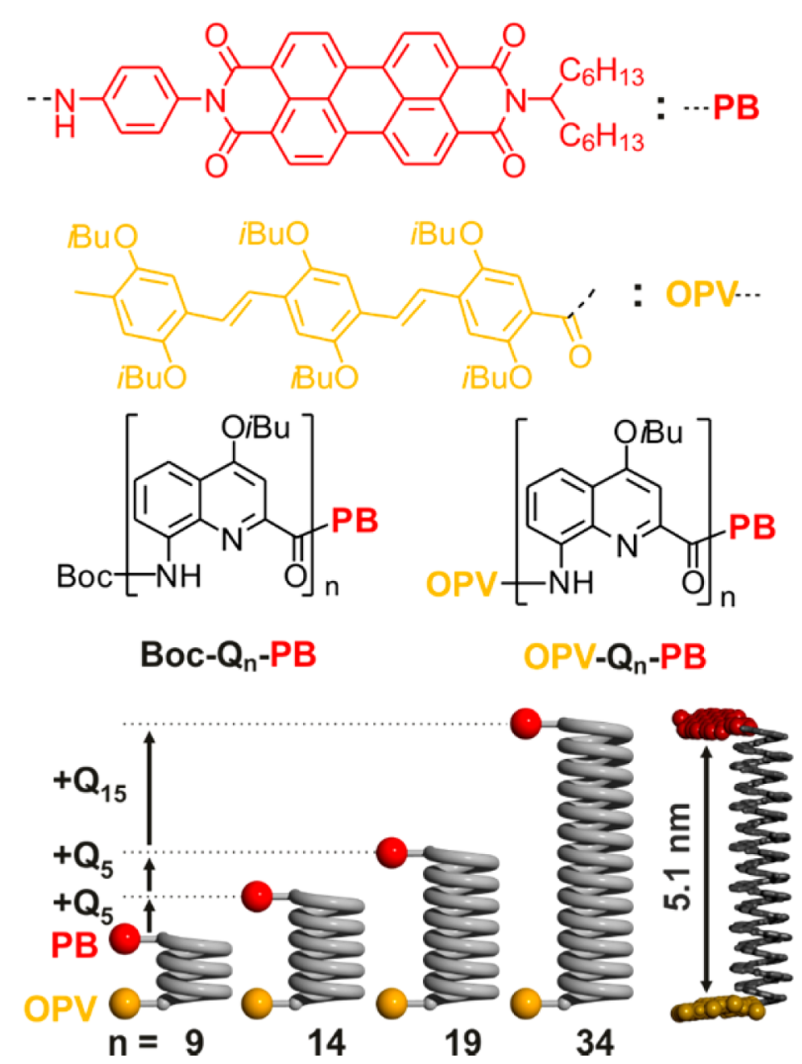

Figure 1. Formulas of studied foldamers $O P V Q_{n} P B$ and $Q_{n} P B$. Schematic spatial representations of the helical structures of OPV $\mathrm{Q}_{n}$ PB with $n=9,14,19$, and 34. The number of helix turns in the cartoon corresponds to the actual number expected in the molecular helix. The bottom right structure shows a color coded energy minimized (Merck molecular force field in Macromodel) model of OPV $Q_{34}$ PB. In this model, alkyl and alkoxy chains have been removed or shortened for clarity.

OPV $Q_{n}$ PB helical oligomers have an exceptional conforma tional stability. For example, even short sequences do not denaturate at $120{ }^{\circ} \mathrm{C}$ in DMSO; helix handedness inversion occurs on the time scale of hundreds of milliseconds for a tetramer, hours for an octamer, and weeks for a hexade camer. $^{56,57}$ Taking advantage of this stability, the initial intention of our earlier study was to evaluate the effect of varying both the orientation and the distance between the donor and acceptor in a controlled manner (i.e., at precise positions with negligible helix dynamics when two turns are reached, $n \geq 5$ ) in order to decipher the respective effects of these two parameters on charge transfer rates. Ultimately, some dependence on both these parameters was demonstrated. However, the main result of the study was the serendipitous discovery that the quinoline carboxamide backbone facilitates charge transfer which was shown to occur very rapidly (tens of picoseconds time scale) and with a small dependence on distance (attenuation factor was measured to be $\beta_{\mathrm{CS}} \sim 0.05$ $\AA^{-1}$ ). Charge transport across these relatively short foldamer bridges was thought to proceed via a superexchange mechanism, i.e., by a direct electron coupling between the donor and acceptor units wave functions facilitated by the bridge. $^{20,58}$

The finding that charge transport is fast in the 18-81 range (through bonds) naturally raised the question of whether aromatic amide foldamers could mediate charge transport over much longer distances and ultimately be of use in photoactive molecular devices. Answering this question was for many years hampered by the considerable challenge of synthesizing long foldamer sequences equipped with complex functional groups. In recent reports, ${ }^{59,60}$ we described optimized methods to produce long quinoline carboxamide oligomers in high yield, high purity and on multigram scales for oligomers as long as a 32 mer that paved the way to the work reported here. We now present the synthesis of oligoamide foldamers bearing $\mathrm{PB}$ and OPV functional terminal functions of unprecedented length. We investigated OPV $Q_{n}$ PB with $n=9,14,18,19,34$, corresponding to interchromophore distances in the range of 14-51 $\AA$ through space and 81-306 $\AA$ through bonds. In addition, Boc $Q_{n}$ PB dyads were studied to gain insight into $Q_{n}$ bridge $\mathrm{PB}$ interactions.

As shown below, photoinduced electron transfer was observed to occur very fast despite the length of the structures. For these long oligomers, the temperature, solvent and length dependence of the charge separation rate are consistent with a hopping mechanism, consisting of several steps, in one of which a hole migrates randomly through the bridge, contrary to the initially proposed superexchange mechanism. Moreover, we report the observation of very long lived charge separated states $\left(>80 \mu \mathrm{s}\right.$ at $15 \mu \mathrm{M}$ in $\left.\mathrm{CH}_{2} \mathrm{Cl}_{2}\right)$, a feature of relevance for photovoltaic applications.

\section{RESULTS}

Molecular Design. In this work, five different rigid foldamer sequences OPV $Q_{n}$ PB with $n=9,14,18,19,34$ with the same electron donor (OPV) and electron acceptor (PB) chromophores linked to the oligo quinolinecarboxamide foldamer termini were successfully synthesized (Figure 1). The molecules were designed to control both the distance between, and the relative orientation of, donor and acceptor chromophores that are expected to protrude from the helix in planes perpendicular to the helix axis. In all compounds except OPV $Q_{18} P B$, the number of quinolines in the bridge is such that OPV and PB adopt a similar orientation in which the dihedral angle $\left(\alpha_{\mathrm{DA}}\right)$ between the chromophores is kept at comparable values (Figure 1 and Table 1). Indeed, solution and solid state studies have demonstrated that $Q_{n}$ helices span almost exactly two turns, i.e., a vertical rise of about $7 \AA$ along the helix axis, every five units. ${ }^{53,60}$ Thus, OPV $\mathrm{Q}_{n}$ PB with $n=$ $9,14,19$, and 34 were expected to have chromophores at a fixed orientation but at a distance that increases by increments of $7 \AA$ from $n=9$ to $n=14$ and $n=14$ to $n=19$, and of $21 \AA$ between $n=19$ and $n=34$. In contrast, OPV $\mathrm{Q}_{18} \mathrm{~PB}$ was expected to differ from OPV $Q_{19} \mathrm{~PB}$ by a minimal change in interchromophore distance, and by a significant change in the 
Table 1. Distance through Space $\left(R_{\mathrm{DA}}\right)$ or through Bridge $\left(R_{\text {bridge }}\right)$ and Dihedral Angle $\left(\alpha_{\text {DA }}\right)$ between the OPV and PB Chromophores

\begin{tabular}{|c|c|c|c|}
\hline & $R_{\mathrm{DA}}(\AA)^{a}$ & $R_{\text {bridge }}(\AA)^{a, b}$ & $\alpha_{\mathrm{DA}}(\operatorname{deg})^{c}$ \\
\hline OPV-Q & 14 & 81 & 58.1 \\
\hline $\mathrm{OPV}-\mathrm{Q}_{4}-\mathrm{PB}$ & 22 & 126 & 66.6 \\
\hline $\mathrm{OPV}-\mathrm{Q}_{18}-\mathrm{PB}$ & 27 & 162 & 289.5 \\
\hline $\mathrm{OPV}-\mathrm{Q}_{19}-\mathrm{PB}$ & 29 & 171 & 77.7 \\
\hline OPV- $\mathrm{Q}_{34}-\mathrm{PB}$ & 51 & 306 & 102.3 \\
\hline
\end{tabular}

${ }^{a}$ Calculated from the first atom of PB to the first atom of OPV beyond amide functions. ${ }^{b}$ Measured along the helix molecular backbone as the sum of all bonds lengths through the helix inner rim. ${ }^{c}$ Dihedral angle between OPV and PB long axes.

relative chromophore orientation of about 360/2.5 $=144^{\circ}$ (Figure S1). In order to determine accurate distances through space $\left(R_{\mathrm{DA}}\right)$ or through bridge $\left(R_{\text {bridge }}\right)$ and dihedral angles $\left(\alpha_{\mathrm{DA}}\right)$ between the chromophores, the energy minimized structures of all oligomers were calculated (Figure S1, Table 1)

Synthesis. The synthesis of OPV $Q_{n}$ PB triads with $n=9$, $14,18,19,34$ is presented in detail in the Supporting Information (schemes S1 to S4). The shortest sequence in this series matches in length with the longest sequence previously described but differs from it by its OPV group. ${ }^{55}$ Indeed, we report the multigram scale synthesis of a new OPV unit functionalized with isobutoxy solubilizing groups. Instead of isobutoxy groups, the previously described OPV $Q_{n} P B$ oligomers incorporated a chiral alkoxy side chain in their OPV units. The presence of the stereogenic centers made NMR analysis of the triads more complicated as the right handed $(P)$ and left handed $(M)$ helical conformations were then diastereomeric and appeared as distinct sets of anisochronous signals in the ${ }^{1} \mathrm{H}$ NMR spectra. In contrast, all $P$ and $M$ helical conformers described here are enantiomers and their NMR spectroscopic features are identical. The PB unit was synthesized as previously described ${ }^{61,62}$ with a free aromatic phenyl amine to be coupled to the $C$ terminus of $Q_{n}$ segments.

The synthetic schemes of these new OPV $Q_{n}$ PB compounds differ substantially from those reported previously, and have been much improved. They make use of the availability of $Q_{4}$, $\mathrm{Q}_{8}$, and $\mathrm{Q}_{6}$ that can be produced in gram quantities via a segment doubling approach ${ }^{60}$ with a $\mathrm{C}$ terminus protected as a methyl ester and an $\mathrm{N}$ terminus having a nitro group or a tert butoxycarbonyl amino (Boc amino) group as amine precursors. Key intermediates included a $Q_{5}$ segment prepared by elongation of $\mathrm{Q}_{4} ; \mathrm{H}_{2} \mathrm{~N} \mathrm{Q}_{8} \mathrm{~PB}$ and $\mathrm{H}_{2} \mathrm{~N} \mathrm{Q}_{17} \mathrm{~PB} ;$ and an OPV $\mathrm{Q} \mathrm{CO}_{2} \mathrm{H}$ monocarboxylic acid (Figure 2), which was

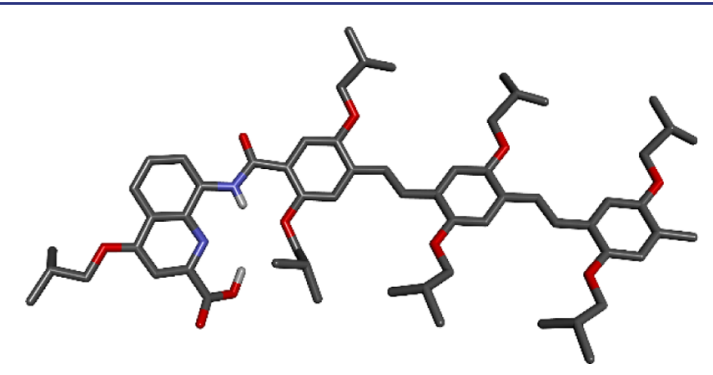

Figure 2. Crystal structure of $\mathrm{OPV} \mathrm{Q} \mathrm{CO}_{2} \mathrm{H}$. Included solvent molecules and hydrogen atoms other than $\mathrm{NH}$ and $\mathrm{OH}$ have been removed for clarity. introduced because of its reliable coupling at the amine terminus of $Q_{n}$ segments, as opposed to the direct coupling of the carboxylic acid of OPV which was less reproducible. Thus, OPV $Q_{9} \mathrm{~PB}$ was readily obtained from $\mathrm{H}_{2} \mathrm{~N} \mathrm{Q}_{8} \mathrm{~PB}$. This latter molecule could be elongated by five units to $\mathrm{H}_{2} \mathrm{~N} \mathrm{Q}_{33} \mathrm{~PB}$, which gave access to OPV $\mathrm{Q}_{4} \mathrm{~PB}$. Similarly, $\mathrm{H}_{2} \mathrm{~N} \mathrm{Q}_{3} \mathrm{~PB}$ was again elongated by five units to give access to $\mathrm{H}_{2} \mathrm{~N} \mathrm{Q} \mathrm{Q}_{8} \mathrm{~PB}$ and then OPV $Q_{19}$ PB. For the preparation of OPV $Q_{18} P B, Q_{6}$ was first elongated to produce $\mathrm{Q}_{7}$ and then $\mathrm{H}_{2} \mathrm{~N} \mathrm{Q}_{7} \mathrm{~PB}$ to which OPV $\mathrm{QCO}_{2} \mathrm{H}$ was coupled. Finally, $\mathrm{Q}_{6}$ was also converted into OPV $\mathrm{Q}_{7} \mathrm{CO}_{2} \mathrm{H}$, which was coupled to $\mathrm{H}_{2} \mathrm{~N}$ $\mathrm{Q}_{7} \mathrm{~PB}$ to yield OPV $\mathrm{Q}_{34} \mathrm{~PB}$. A new scheme to prepare OPV $\mathrm{Q}_{4} \mathrm{~PB}$ with the new OPV side chains is also reported but the photophysical studies for this compound were not repeated (see Supporting Information). In addition, analogous molecular dyad systems lacking the electron donor OPV were prepared as well: Boc $Q_{n}$ PB where $n=1,2,4,8,17$.

Spectroscopic Studies. Photoinduced electron transfer (PET), charge (electron-hole) separation (CS) and charge recombination (CR) processes in OPV $Q_{n} P B$ systems in solution were studied using subpico and nanosecond transient absorption spectroscopy (TRABS) and complementary time resolved fluorescence spectroscopy in the temperature range $180-298 \mathrm{~K}$. Along with time resolved techniques, steady state electronic absorption and photoluminescence spectroscopy were used to obtain further information (see Supporting Information). Spectroscopic studies were performed in chlorinated solvents in which all compounds mentioned above are highly soluble and for the purpose of comparing new results with previous ones. ${ }^{55}$ The solvents were thoroughly deoxygenated by multiple freeze-pump-thaw cycles, since it was found that, in the presence of oxygen, OPV photodamage occurs for OPV $\mathrm{Q}_{n} \mathrm{~PB}$ samples with $n>9$. Dichloromethane $\left(\mathrm{CH}_{2} \mathrm{Cl}_{2}\right.$, spectroscopic grade, dielectric constant $\left.\varepsilon=8.93^{63}\right)$ and chloroform $\left(\mathrm{CHCl}_{3}\right.$, spectroscopic grade, $\left.\varepsilon=4.81^{63}\right)$ were used to investigate the effect of the solvent dielectric properties on photoinduced electron transfer and charge separation. Some measurements recorded in toluene showed more complex behavior such as double exponential PB fluorescence decays for longer variants. In addition, charge separation from donor to acceptor is disfavored in less polar solvents and does not occur in toluene for bridges as short as OPV $Q_{19} \mathrm{~PB}$. Studies in toluene would thus not allow one to compare the full range of bridge lengths and were not pursued. Nevertheless, several experiments were carried out in toluene for comparison, to assess possible external heavy atom effects (EHE) induced by chlorine atoms of the solvents. ${ }^{64}$ Our results demonstrate no significant influence of EHE on intersystem crossing in triads/ dyads (vide infra).

Electronic Absorption Spectroscopy. The absorption spectra of the individual components of the triads, i.e., OPV, PB and $Q_{n}$ taken as separate entities, show bands in distinct regions which allows to envisage chromophore specific excitation: $350-450 \mathrm{~nm}$ for OPV and 450-550 nm for PB, while $\mathrm{Q}_{n}$ oligomers absorb in the $250-400 \mathrm{~nm}$ range. The $\mathrm{UV} /$ vis absorption spectra of the studied triads (Figure S2) are qualitatively similar to the sum of the spectra of the individual components (Figure S3) and could be divided into the three regions ascribed to $\mathrm{Q}_{n}, \mathrm{OPV}$ and $\mathrm{PB}$. The OPV and $\mathrm{PB}$ absorption bands show only small fluctuations in molar absorption coefficients that are likely caused by changes in electronic structure and environment. The structure and spectral position of the vibronic bands of $\mathrm{PB}$ are similar for 
all triads and dyads. At the concentration at which the experiments were conducted $\left(1.5 \times 10^{-5} \mathrm{M}\right.$ for TRABS and $\sim 10^{-6} \mathrm{M}$ for fluorescence), the absorption spectra display characteristic vibronic progressions, indicating the absence of any aggregation phenomena. ${ }^{65,66}$ Absorption bands of individ ual $\mathrm{PB}, \mathrm{OPV}$ and quinoline units do not vary significantly upon incorporation into triads or dyads. This indicates the absence of strong conjugation between the chromophores and adjacent quinoline units, and between quinoline units themselves, in the ground state. Nevertheless, the molar absorption coefficient of $\mathrm{Q}_{n}$ does not increase linearly with the number of bridge units, neither in Boc $Q_{n} P B$ dyads nor in OPV $Q_{n} P B$ triads. Some hypochromic effect is observed and the molar absorption per quinoline unit decreases with length. Structural elements of the bridge lying on the main axis of the triad appear to screen each other causing reduction of absorption (Figure S4-S5).

Photoluminescence Spectroscopy. Earlier studies of shorter OPV $Q_{n} P B$ triads showed that excitation of the $P B$ moiety resulted in a ca. 150 fold decrease of fluorescence. This was attributed to efficient quenching via an electron transfer process toward the excited $\mathrm{PB}$ chromophore. ${ }^{55}$ Fluorescence quenching thus offers a method to quantify electron transfer rates and efficiency in OPV $Q_{n}$ PB triads and Boc $Q_{n}$ PB dyads. Measurements of the emission quantum yield $\left(\Phi_{\mathrm{fl}}\right)$ and changes in luminescence lifetime $(\tau)$ in these multicomponent systems relative to the reference Boc PB fluorophore $\left(\Phi_{\mathrm{fl}}=\right.$ 0.88, $\tau=4.00 \mathrm{~ns}$ in $\mathrm{CH}_{2} \mathrm{Cl}_{2} ; \Phi_{\mathrm{fl}}=0.81, \tau=3.85 \mathrm{~ns}$ in $\mathrm{CHCl}_{3}$ ) allows estimation of the rate $\left(k_{\mathrm{CT}}\right)$ and efficiency of electron transfer according to eq 1 .

$$
k_{\mathrm{CT}}=k-k_{0}=\frac{1}{\tau}-\frac{1}{\tau_{0}}
$$

in which $k$ is the emission rate of the quenched fluorophore in triad and dyad systems and $k_{0}$ is the fluorescence rate of unquenched Boc $\mathrm{PB}, \tau$ and $\tau_{0}$ are the corresponding lifetimes of fluorescence, respectively. Table 2 lists the fluorescence

Table 2. Fluorescence Quantum Yields $\left(\boldsymbol{\Phi}_{\mathrm{fl}}\right)$ and Emission Lifetimes $(\tau)$ of Dyads and Triads at $295 \mathrm{~K}$ in $\mathrm{CH}_{2} \mathrm{Cl}_{2}$ and $\mathrm{CHCl}_{3}$

\begin{tabular}{|c|c|c|c|c|}
\hline samples & $\begin{array}{c}\Phi_{\mathrm{fl}} \text { in } \\
\mathrm{CH}_{2} \mathrm{Cl}_{2}\end{array}$ & $\underset{\mathrm{CHCl}_{\mathrm{fl}} \text { in }}{\mathrm{CHCl}}$ & $\begin{array}{l}\tau, \text { ps in } \\
\mathrm{CH}_{2} \mathrm{Cl}_{2}\end{array}$ & $\begin{array}{l}\tau, \text { ps in } \\
\mathrm{CHCl}_{3}\end{array}$ \\
\hline Boc- $Q_{1}-\mathrm{PB}$ & 0.037 & 0.070 & 335 & 670 \\
\hline Boc- $_{2}-\mathrm{PB}$ & 0.022 & 0.040 & 230 & 420 \\
\hline Boc- $Q_{4}-P B$ & 0.015 & 0.017 & 118 & 150 \\
\hline Boc- $Q_{s}-\mathrm{PB}$ & 0.006 & 0.006 & 60 & 61 \\
\hline Boc- $Q_{17}-\mathrm{PB}$ & 0.006 & 0.006 & 58 & 59 \\
\hline OPV-Q-PB & 0.006 & 0.005 & 55 & 56 \\
\hline $\mathrm{OPV}-\mathrm{Q}_{4}-\mathrm{PB}$ & 0.006 & 0.005 & 60 & 55 \\
\hline $\mathrm{OPV}-\mathrm{Q}_{18}-\mathrm{PB}$ & 0.007 & 0.006 & 60 & 57 \\
\hline OPV-Q ${ }_{19}-\mathrm{PB}$ & 0.006 & 0.006 & 55 & 53 \\
\hline $\mathrm{OPV}-\mathrm{Q}_{34}-\mathrm{PB}$ & 0.006 & 0.007 & 60 & 60 \\
\hline Boc-PB & 0.88 & 0.81 & 4000 & 3850 \\
\hline
\end{tabular}

quantum yields and emission lifetime values of the studied dyads and triads. For $n \geq 8$, the triads and dyads showed strong emission quenching which resulted in shortening of emission lifetime down to $60 \mathrm{ps}$, corresponding to electron transfer rates of $1.7 \times 10^{10} \mathrm{~s}^{-1}$. This strong lifetime decrease correlates well with the extent of fluorescence quenching (ca. 150 fold with respect to the $\mathrm{Boc} \mathrm{PB}$ ) observed in steady state measurements of fluorescence quantum yield in both $\mathrm{CH}_{2} \mathrm{Cl}_{2}$ and $\mathrm{CHCl}_{3}$
(Table 2, Figure S8). Shorter dyads (Boc $\mathrm{Q}_{n} \mathrm{~PB}$ with $n=1,2$, 4) showed lower $\mathrm{PB}$ fluorescence quenching rates, in the range $2.7 \times 10^{9}$ to $8.2 \times 10^{9} \mathrm{~s}^{-1}$ in $\mathrm{CH}_{2} \mathrm{Cl}_{2}(\tau=118-335 \mathrm{ps}$, Table 2 , Figure S9-10).

Excitation spectra recorded on the weak residual emission from the quenched PB electron acceptor $(\lambda=576 \mathrm{~nm}$, Figure 3 ) revealed efficient electronic energy transfer from the OPV

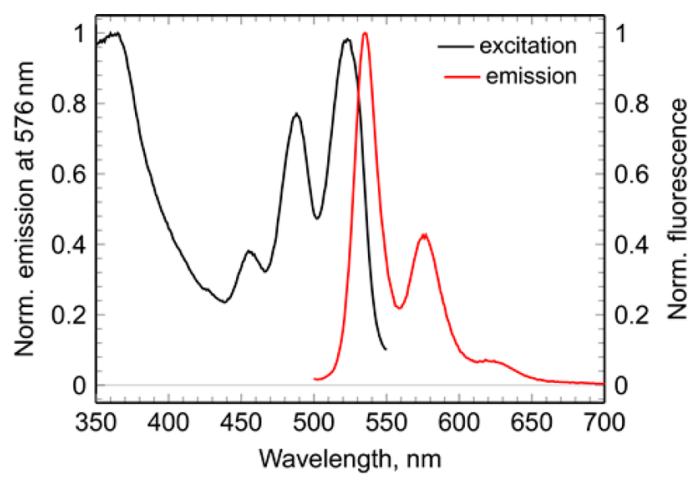

Figure 3. Excitation $\left(\lambda_{\mathrm{obs}}=576 \mathrm{~nm}\right)$ and emission $\left(\lambda_{\mathrm{exc}}=490 \mathrm{~nm}\right)$ spectra of OPV ${ }_{19} \mathrm{~PB}$ in $\mathrm{CH}_{2} \mathrm{Cl}_{2}$.

$\mathrm{Q}_{n}$ chromophore to $\mathrm{PB}$. Depending on the length of the $\mathrm{Q}_{n}$ bridge, the time constant $(\tau)$ of energy transfer ranges from subnanosecond to nanosecond, e.g., $\tau=10$ ps for OPV $\mathrm{Q}_{9} \mathrm{~PB}$ (see Figure S12a) and $\tau>2000$ ps for OPV Q ${ }_{34} \mathrm{~PB}$. Interchromophore electronic energy transfer (EET) processes, which occur before electron transfer processes of interest if the OPV is excited, will not be discussed further here. Indeed, selective excitation of the $\mathrm{PB}$, thereby effectively avoiding EET, was performed throughout.

Transient Absorption Spectroscopy (TRABS). Details of the sequence of processes following photoexcitation of these multicomponent architectures, including electron transfer, could be determined using TRABS studies. Measurements were performed simultaneously at a number of wavelengths and at a certain time delay after the excitation pulse (time gated spectra). A collection of spectra at different time delays constitutes the time resolved spectrum (Figure 4). A high dynamic range streak camera with broad time range detection (50 ps to $1 \mathrm{~ms}$ ) was used to register transient signals, allowing studies of the evolution of transient signals with time constants ranging from $60 \mathrm{ps}$ to $100 \mu \mathrm{s}$. Additionally, ultrafast TRABS experiments were performed (Figure S6) in order to better resolve fast electron transfer processes.

TRABS maps of Boc Q $\mathrm{PB}$ recorded at $298 \mathrm{~K}$ in $\mathrm{CHCl}_{3}$ (Figure 4A) show that, after excitation of $\mathrm{PB}$, positive absorption signatures corresponding to both $\mathrm{PB} S_{n} \leftarrow S_{1}$ and $\mathrm{PB}$ anion radical $\left(\mathrm{PB}^{\bullet-} \text {, centered at } 700 \mathrm{~nm}\right)^{67}$ and to quinoline cation radical $\left(\mathrm{Q}^{\bullet+}\right.$, centered at $390 \mathrm{~nm}$, Figure S11a) ${ }^{68}$ appear simultaneously with a time constant of $\sim 60$ ps. The same observation was made via femtosecond TRABS measurements (Figure S11b). In contrast, maps of OPV Q PB (Figure 4B, Figure S12b) do not reveal an absorption band which could be attributed to $\mathrm{Q}^{\bullet+}$, following excitation. Instead, OPV ground state bleaching (GSB) is observed, concomitant with the appearance of $\mathrm{a} \mathrm{PB}^{\bullet-}$ band $(\tau \approx 60 \mathrm{ps})$ and of an $\mathrm{OPV}^{\bullet+}$ band. However, for longer $Q_{n}$ bridges, starting from OPV $Q_{4} P B$, OPV GSB and $\mathrm{OPV}^{\bullet+}$ bands appearance clearly occurs with some time delay with respect to the appearance of the $\mathrm{PB}^{\bullet-}$ absorption band (Figure 4C, D). Moreover, for these longer 


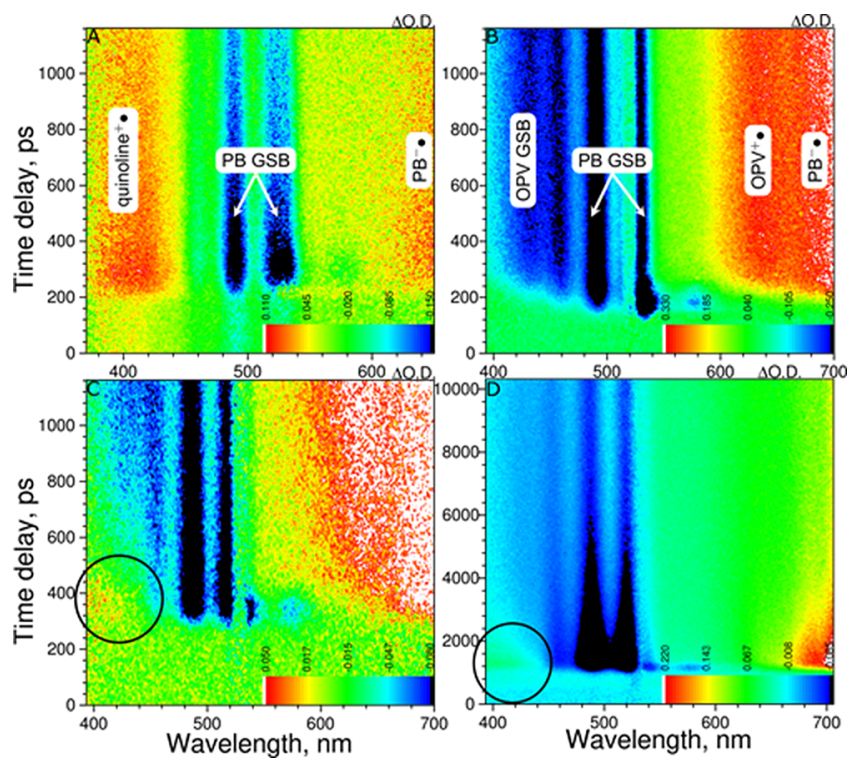

Figure 4. TRABS maps of (A) Boc $\mathrm{Q}_{8} \mathrm{~PB}\left(\lambda_{\text {exc }}=510 \mathrm{~nm}\right)$; (B) OPV $\mathrm{Q}_{9}$ PB $\left.\lambda_{\text {exc }}=510 \mathrm{~nm}\right) ;(\mathrm{C})$ OPV $\mathrm{Q}_{19}$ PB $\left(\lambda_{\text {exc }}=532 \mathrm{~nm}\right)$; (D) OPV $\mathrm{Q}_{34} \mathrm{~PB}\left(\lambda_{\text {exc }}=532 \mathrm{~nm}\right)$, at $298 \mathrm{~K}$ in $\mathrm{CHCl}_{3}$. Positive absorption is shown in yellow and red, whereas ground state bleaching (GSB) is shown in blue. Circles indicate the presence of $\mathrm{Q}^{\bullet+}$ absorption band. In (D), the vertical scale is expanded to $10 \mathrm{~ns}$ to accommodate the slower hole transfer through the long $\mathrm{Q}_{34}$ bridge. A better view with higher contrast of the quinoline radical band is presented in Figure S18.

bridges $(n \geq 14)$, the presence of quinoline cation radical $\mathrm{Q}^{\bullet+}$ absorption band at $390 \mathrm{~nm}$ is present in TRABS maps at early stages after excitation pulse (indicated by circles).

To determine the rate of overall charge separation in triad systems, i.e., the electron transfer between $\mathrm{PB}$ and OPV, we monitored the rate of OPV GSB (Figure S13), that is the rate at which the HOMO of OPV is oxidized to give $\mathrm{OPV}^{\bullet+}$. OPV GSB kinetics were fitted to an exponential function and the corresponding time constant parameter was attributed to charge separation. Good fits were obtained following this time convention (see Figure S13). Nevertheless, here, monoexponential analysis is purely phenomenological. ${ }^{83}$ Similarly, time resolved PB fluorescence decay was fitted to an exponential function to determine the rate of electron transfer from the $Q_{n}$ bridge to $P B$ that causes emission quenching.

In order to elucidate the mechanism of electron transfer, time resolved fluorescence and TRABS were conducted at different temperatures in the range of $180-298 \mathrm{~K}$ in $\mathrm{CH}_{2} \mathrm{Cl}_{2}$ and $210-298 \mathrm{~K}_{\text {in }} \mathrm{CHCl}_{3}$ (see Supporting Information). These experiments allowed the determination of electron transfer activation energies (Table 3, Figures 5, 6) based on an Arrhenius type dependence (eq 2), where $k_{\mathrm{CT}}$, rate of charge transfer; $\Delta G$, electron transfer activation energy; $k_{\mathrm{B}}$, Boltzmann constant; $A$, pre exponential factor; $T$, temperature.

$$
k_{\mathrm{CT}}=A \cdot \exp \left(\frac{-\Delta G}{k_{\mathrm{B}} T}\right)
$$

The temperature dependence of charge separation and fluorescence quenching rates are presented in Figures 5 and 6, respectively, as plots of $1 / T$ versus the logarithm of $k_{\mathrm{CT}}$. These plots reveal an intriguing phenomenon: the activation energy of electron transfer, $\Delta G$, determined by monitoring OPV ground
Table 3. Activation Energy $\Delta G$ of Initial Charge Injection and Overall Charge Separation

\begin{tabular}{|c|c|c|c|c|}
\hline \multirow[b]{2}{*}{ samples } & \multicolumn{2}{|c|}{$\Delta G(\mathrm{eV})$ charge injection } & \multicolumn{2}{|c|}{$\begin{array}{c}\Delta G(\mathrm{eV}) \text { charge } \\
\text { separation }\end{array}$} \\
\hline & $\mathrm{CH}_{2} \mathrm{Cl}_{2}$ & $\mathrm{CHCl}_{3}$ & $\mathrm{CH}_{2} \mathrm{Cl}_{2}$ & $\mathrm{CHCl}_{3}$ \\
\hline Boc- $Q_{s}-\mathrm{PB}$ & 0.105 & & & \\
\hline $\mathrm{OPV}-\mathrm{Q}_{-}-\mathrm{PB}$ & 0.098 & 0.090 & 0.105 & 0.090 \\
\hline $\mathrm{OPV}-\mathrm{Q}_{14}-\mathrm{PB}$ & 0.105 & 0.080 & 0.087 & 0.082 \\
\hline $\mathrm{OPV}-\mathrm{Q}_{18}-\mathrm{PB}$ & 0.095 & 0.072 & 0.078 & 0.075 \\
\hline $\mathrm{OPV}-\mathrm{Q}_{19}-\mathrm{PB}$ & 0.100 & 0.071 & 0.065 & 0.062 \\
\hline $\mathrm{OPV}-\mathrm{Q}_{34}-\mathrm{PB}$ & 0.088 & 0.080 & 0.045 & \\
\hline
\end{tabular}

$\mathrm{T}, \mathrm{K}$

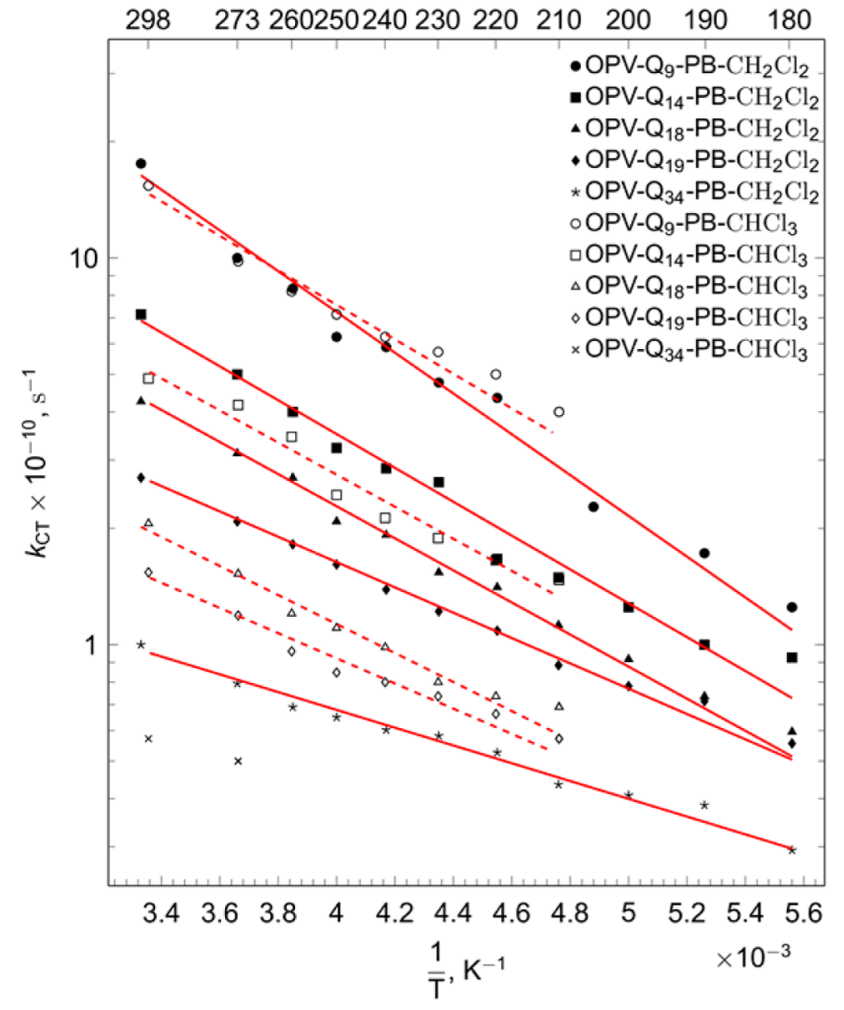

Figure 5. Temperature dependence of charge separation rate between $\mathrm{OPV}$ and $\mathrm{PB}$ in OPV $\mathrm{Q}_{n} \mathrm{~PB}$ in $\mathrm{CH}_{2} \mathrm{Cl}_{2}$ and $\mathrm{CHCl}_{3}$, calculated from the rate of OPV GSB appearance $\left(\lambda_{\text {exc }}=532 \mathrm{~nm}\right)$. Charge separation does not occur for OPV $\mathrm{Q}_{34} \mathrm{~PB}$ in $\mathrm{CHCl}_{3}$ at temperatures lower than $273 \mathrm{~K}$ (see below for explanation). Solid and dotted lines represent linear fits of data recorded in $\mathrm{CH}_{2} \mathrm{Cl}_{2}$ and $\mathrm{CHCl}_{3}$, respectively.

state bleaching, shows a monotonic decrease upon increasing the number of quinolines in the bridge (see Table 3, charge separation). Meanwhile activation energies determined from PB luminescence quenching are almost identical for all studied samples (see Table 3, charge injection). An influence of solvent dielectric permeability was observed, characterized by a slightly lower activation energy in $\mathrm{CHCl}_{3}$ than in $\mathrm{CH}_{2} \mathrm{Cl}_{2}$ but the difference is minimal.

Charge Recombination. The charge separated state (CSS) of the studied triads $\mathrm{OPV}^{\bullet+} \mathrm{Q}_{n} \mathrm{~PB}^{\bullet-}$ is formed in the subnanosecond to nanosecond range. We observed that charge recombination-i.e., the return to the ground state-is much slower. The TRABS kinetics of the shortest triad OPV $\mathrm{Q}_{9} \mathrm{~PB}$ in $\mathrm{CHCl}_{3}$ shows that the absorption bands corresponding to $\mathrm{PB}^{\bullet-}$ (centered at $720 \mathrm{~nm}$ ) and $\mathrm{OPV}^{\bullet+}$ (centered at $625 \mathrm{~nm}$ ) 


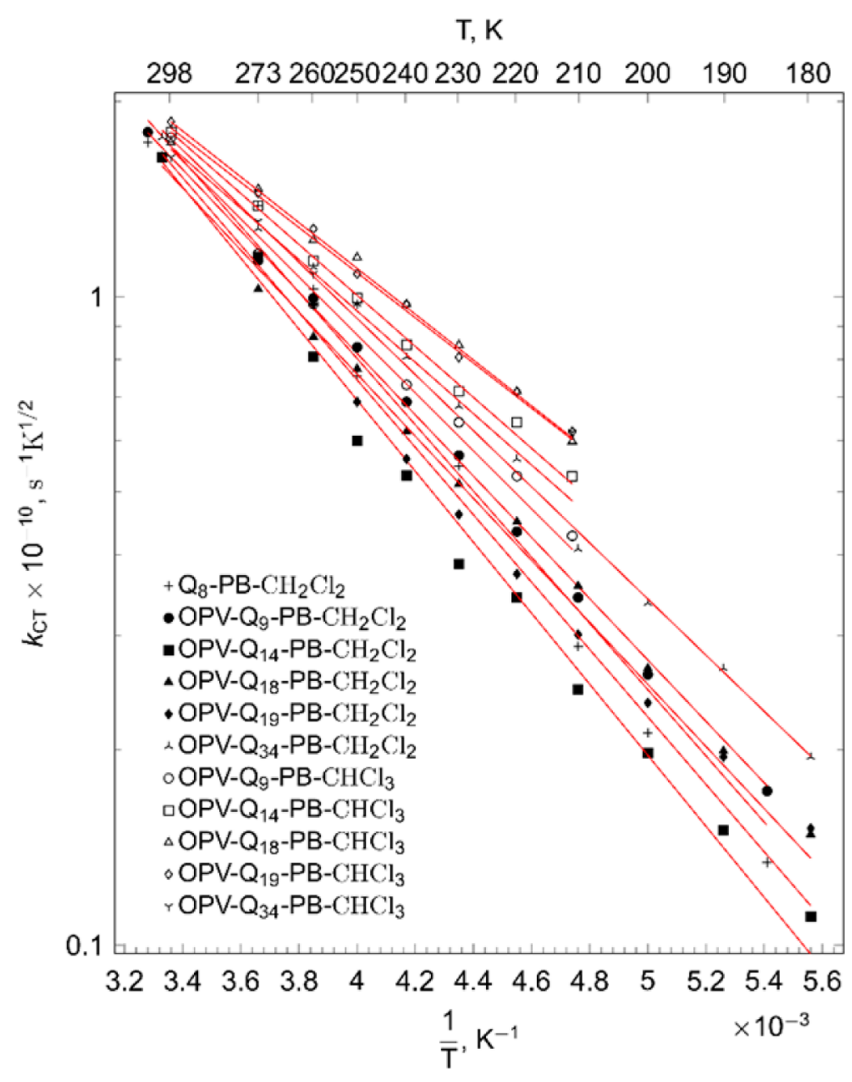

Figure 6. Temperature dependence of the charge injection rate from the quinoline bridge into excited PB low lying SOMO, calculated from emission rates $\left(\lambda_{\text {exc }}=532 \mathrm{~nm}, \lambda_{\text {obs }}=575 \mathrm{~nm}\right.$ ) of PB (see SI, Correction of rate of electron injection transfer).

relax with the same time constants, $\tau_{\mathrm{CR}}=150 \mathrm{~ns}$ (Figure S14). In $\mathrm{CH}_{2} \mathrm{Cl}_{2}$, a more polar solvent, $\tau_{\mathrm{CR}}=450 \mathrm{~ns}$ at a concentration of $\sim 15 \mu \mathrm{M}$. The disappearance of $\mathrm{PB}^{\bullet-}$ is accompanied by the formation of the $\mathrm{PB}$ charge recombined triplet state, which is characterized by intense absorption, centered at $502 \mathrm{~nm}$ (Figure 7), shifted from $510 \mathrm{~nm}$ observed previously. ${ }^{69}$ The triplet state only appeared in this context. As shown in Figure S17a, the absorption band of $\mathrm{OPV}^{\bullet+}$ and $\mathrm{PB}^{\bullet-}$ for longer triads $\mathrm{OPV}^{\bullet+} \mathrm{Q}_{14} \mathrm{~PB}^{\bullet-}$, $\mathrm{OPV}^{\bullet+} \mathrm{Q}_{19} \mathrm{~PB}^{-}$, and also $\mathrm{OPV}^{\bullet+} \mathrm{Q}_{34} \mathrm{~PB}^{\bullet-}$ are still observed more than $80 \mu \mathrm{s}$ after the excitation pulse. This demonstrates an extremely long CSS lifetime. Charge recombination occurs in a similar manner in

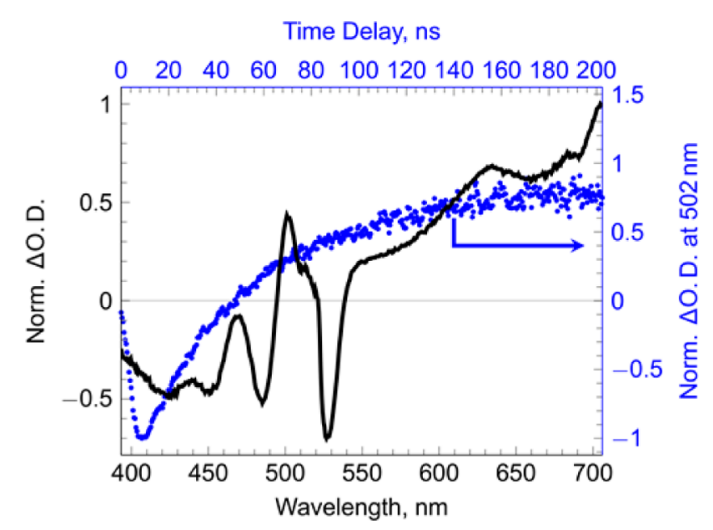

Figure 7. TRABS spectrum of OPV $\mathrm{Q}_{0} \mathrm{~PB}$ in $\mathrm{CHCl}_{3}\left(\lambda_{\text {exc }}=532 \mathrm{~nm}\right.$, time scale 100-200 ns) and O.D. change at $502 \mathrm{~nm}$. toluene, i.e., from CSS singlet to a charged recombined triplet state. In the case of OPV $\mathrm{Q}_{9} \mathrm{~PB}$, charge recombination is faster in toluene (time constant $\sim 15 \mathrm{~ns}$, Figure S14c) than $\mathrm{CH}_{2} \mathrm{Cl}_{2}$ (time constant $450 \mathrm{~ns}$, Figure S14b) and in chloroform (time constant $>150 \mathrm{~ns}$, Figure S14a). This suggests no heavy atom effect in chlorinated solvents that would favor intersystem crossing to triplet states. Furthermore, we find that the slow charge recombination to the triplet state is concentration dependent (e.g., for OPV $\mathrm{Q}_{19} \mathrm{~PB}, \sim 60 \mu \mathrm{s}$ at $15 \mu \mathrm{M}$ and $\sim 34 \mu$ s at $130 \mu \mathrm{M})$ suggesting the involvement of bimolecular processes.

The relaxation of the CSS of dyads $\mathrm{Q}^{\bullet+}{ }_{n} \mathrm{~PB}^{\bullet-}$ also occurs with the concomitant formation of a $\mathrm{PB}$ triplet state with a time constant at $298 \mathrm{~K}$ of $750 \mathrm{ps}$ in $\mathrm{CH}_{2} \mathrm{Cl}_{2}$ and $400 \mathrm{ps}$ in toluene (Figure $\mathrm{S} 15 \mathrm{a}, \mathrm{b}$ ). This similarity again suggests no strong role of the solvent in these processes.

The relaxation of the charged recombined PB triplet state occurs on a much longer time scale than charge recombina tion-hundreds of microseconds (Figure S16-17). Time constants were measured to be $>340 \mu \mathrm{s}$ for OPV Q $\mathrm{PB}$ and $>420 \mu$ s for the longer OPV $\mathrm{Q}_{n}$ PB triads $(n=14,18,19,34)$ in $\mathrm{CHCl}_{3}$. This process as well was found to be largely independent from solvent (Figure $\mathrm{S} 17 \mathrm{~b}$ ) and shows some concentration dependence: for OPV Q ${ }_{19} \mathrm{~PB}$ in $\mathrm{CH}_{2} \mathrm{Cl}_{2}$, relaxation of triplet state occurs at $>360 \mu \mathrm{s}$ at $15 \mu \mathrm{M}$ and $\sim 86$ at $130 \mu \mathrm{M}$.

\section{DISCUSSION}

Evidence for the Contribution of a Hopping Charge Transfer Mechanism. Depending on the process, electron transfer rates were found in three distinct time scales: initial PB emission quenching occurs in the subnanosecond time scale, $\mathrm{OPV}$ GSB and the concomitant appearance of $\mathrm{OPV}^{\bullet+}$ absorption occur in the nanosecond time scale, and charge separated state lifetimes are found in the microsecond time scale. The rate of $\mathrm{PB}$ emission quenching is independent of $\mathrm{Q}_{n}$ bridge length and equal to 60 ps for values of $n>8$ (Table 2), while it varies with $\mathrm{n}$ for shorter variants (see below). In contrast, OPV GSB is increasingly slow as the $Q_{n}$ bridge is lengthened. OPV GSB occurs almost 20 times faster in the shortest triad OPV $Q_{9} \mathrm{~PB}\left(\tau_{\mathrm{GSB}}=1.75 \times 10^{10} \mathrm{~s}^{-1}\right)$ than in the longest $\mathrm{OPV} \mathrm{Q}_{34} \mathrm{~PB}\left(\tau_{\mathrm{GSB}}=9.6 \times 10^{8} \mathrm{~s}^{-1}\right)$. This alone suggests a multistep charge separation pathway in these triads: if charge transfer occurred in a single step, OPV GSB appearance and $\mathrm{PB}$ emission lifetimes would both be expected to depend on foldamer bridge length.

$\mathrm{PB}$ emission quenching is due to the formation of the long lived $\mathrm{PB}^{\bullet-}$. TRABS data (see Boc $\mathrm{Q}_{8} \mathrm{~PB}$ in Figure $4 \mathrm{~A}$ and S11a) show that the absorption bands of $\mathrm{Q}^{\bullet+}$ (centered at $390 \mathrm{~nm}$ ) and $\mathrm{PB}^{\circ-}$ appear at the same rate. This leads to the conclusion that, after excitation of $\mathrm{PB}$, electron transfer occurs from the quinoline bridge HOMO toward the PB lowest lying SOMO with a rate of $1.7 \times 10^{10} \mathrm{~s}^{-1}(\tau=\sim 60 \mathrm{ps}$ for $n>8)$. At $298 \mathrm{~K}$ the OPV GSB appears with a time delay (Figure 4C, D, Figure S13, Table 2) relative to the $\mathrm{PB}^{\bullet-}$ band for triads with $n \geq 14$ (the case $n=9$ will be considered below). This is consistent with a two step electron transfer in which the reduction of excited $\mathrm{PB}$ is followed by (and not synchronous with) the oxidation of OPV. Thus, a global picture emerges in which the reduction of excited $\mathrm{PB}$ results in the injection of a hole in the $Q_{n}$ bridge through which it migrates toward the OPV electron donor that it ultimately oxidizes (Figure 8). 


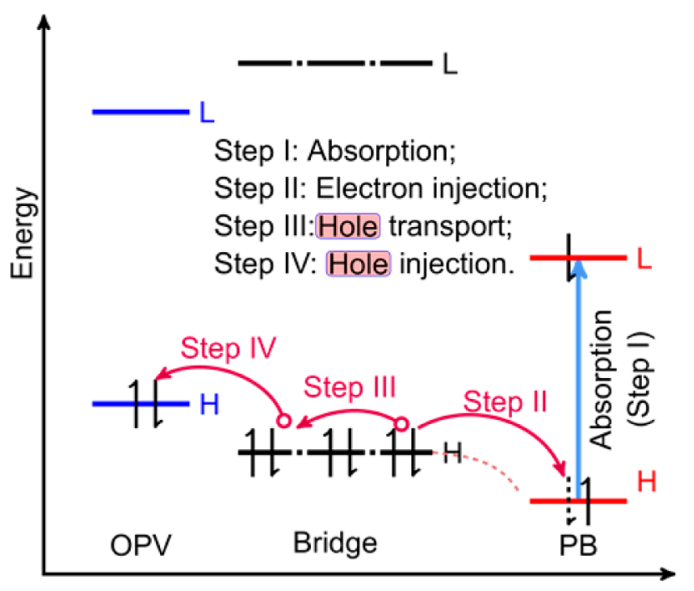

Figure 8. Simplified frontier orbital diagram of electron transfer between $\mathrm{PB}$ and OPV through the $\mathrm{Q}_{\mathfrak{n}}$ foldamer bridge. The small red circles represent holes.

In the case of OPV $\mathrm{Q}_{9} \mathrm{~PB}$, the rates of electron transfer from the quinoline unit to $\mathrm{PB}$ and further hole transfer toward OPV are equal to each other at $298 \mathrm{~K}\left(1.7 \times 10^{10} \mathrm{~s}^{-1}\right)$. For this shorter triad, a two step hopping mechanism for electron transfer may not be unambiguously discriminated from a one step mechanism as in, for example, a superexchange. However, low temperature studies allowed to demonstrate the prevalence of a two step mechanism for OPV $Q_{2} \mathrm{~PB}$ as well. Already at $273 \mathrm{~K}$, a difference between the rates of $\mathrm{PB}$ emission quenching ( $\tau=85$ ps $)$ and OPV GSB $(\tau=100$ ps $)$ can be observed (Figure 5, 6). This difference increases upon lowering temperature further. In addition, the temperature dependence of electron transfer rate between PB and OPV shows that this process has a positive activation energy, whereas a negative activation energy is expected in the superexchange mecha nism. $^{70-72}$ In other words, charge separation via a super exchange may be anticipated to become faster upon cooling because cooling results in an increase of electron coupling between donor and acceptor due to the decrease of thermally induced disorder. Even though the lack of negative activation energy alone does not allow one to completely rule out a superexchange mechanism, ${ }^{73}$ it remains a strong indication. Previous studies on short OPV $\mathrm{Q}_{n}$ PB triads $(n=2,4,5,9)$ led to the conclusion that charge transfer between $\mathrm{PB}$ and OPV is governed by a superexchange mechanism. ${ }^{55}$ The present investigation shows that a hopping mechanism contributes when $n \geq 9$.

Efficiency of Charge Injection into the Foldamer Bridge. We note that $\mathrm{PB}$ quenching rates in dyads Boc $\mathrm{Q}_{n} \mathrm{~PB}$ $(n=1,2,4,8$, Figure S9-10) increase almost exponentially from $n=1\left(3 \times 10^{9} \mathrm{~s}^{-1}, \tau=330 \mathrm{ps}\right)$ to $n=8\left(1.7 \times 10^{10} \mathrm{~s}^{-1}, \tau\right.$ $=60 \mathrm{ps}$ ) while they remain constant for larger $\mathrm{n}$ values (Table 2). A possible explanation may be drawn from the effects of geometry on electronic coupling between $\mathrm{PB}$ and subsequent quinoline units, which define electron transfer rates. Applying Marcus theory of electron transfer in the nonadiabatic regime, considering that the quinoline $\mathrm{PB}$ electronic coupling is weak, $k_{\mathrm{CT}}$ may be expressed as in eq $3:^{74}$

$$
k_{\mathrm{CT}}=\frac{2 \pi}{\hbar} V_{\text {eff }}^{2} \sqrt{\frac{1}{4 \pi \lambda k_{\mathrm{B}} T}} \exp \left(\frac{-\Delta G^{\ddagger}}{k_{\mathrm{B}} T}\right)
$$

where $\Delta G^{\ddagger}=\left(\lambda+\Delta G^{\mathrm{RP}}\right)^{2} / 4 \lambda$, with $\Delta G^{\mathrm{RP}}$ as the free energy change of radical ion pair formation, $\lambda$ as the reorganization energy, and $V_{\text {eff }}^{2}$ as electronic coupling between initial and final states, $T$, temperature, $k_{\mathrm{B}}$, Boltzmann constant. Experiments were performed in low polarity solvents and, due to the large sizes of the acceptor and donor, $\lambda$ is assumed to be dominated by inner sphere reorganization. ${ }^{73}$ Note that the activation energy, $\Delta G$, of electron transfer from the quinoline bridge to $\mathrm{PB}$ varies slightly between different samples and equals to $\sim 0.1$ $\mathrm{eV}$ in $\mathrm{CH}_{2} \mathrm{Cl}_{2}$ (Table 3). This is also true for shorter dyads Boc $\mathrm{Q}_{1}$ PB and Boc $\mathrm{Q}_{2}$ PB (Figure S19). The values for $\Delta G^{\ddagger}$ are slightly different (see Table S1) from $\Delta G$, as the influence of $\sqrt{ }(1 / T)$ is to be taken into account. The activation energy of electron transfer rate does not depend on length of the bridge, and we can conclude that the energetic term of eq 3 does not play important role in the bridge length dependence of charge transfer rate. This points to electron coupling $V_{\text {eff }}^{2}$ as the origin of this dependence.

The Boc $Q_{8}$ PB structure spans three full helix turns; it has a rigid geometry with a well defined relative orientation of the quinoline units and the PB chromophore. At lower values of $n$, the helix spans a lower number of turns. This may result in a less well defined geometry at the helix PB linkage, providing PB with a larger conformational freedom with respect to the bridge and thus a diminished electron coupling between bridge and $\mathrm{PB}$. As explained in the introduction, earlier studies have shown that these helices are so stable that conformational dynamics are extremely slow. Yet the helix PB linkage might be influenced by the size and rigidity of the neighbor helix. Here, we assume that electron transfer occurs from the quinoline covalently attached to PB. Meanwhile, electron transfer might also occur from subsequent quinolines that come in close proximity to $\mathrm{PB}$, albeit less efficiently.

Length Dependence of Hole Transport Rate through the $Q_{n}$ Bridge. We have shown that electron transfer between $\mathrm{PB}$ and OPV mediated by a foldamer bridge consists of two steps: electron transfer from the bridge to the acceptor (PB), i.e., charge injection into the bridge, and propagation of a hole through the bridge to the donor (OPV). The propagation of the hole through the bridge itself may be mediated by either a superexchange or a hopping mechanism. An analysis of the bridge length dependence of the rate of hole transport allows to discriminate between these two mechanisms. Indeed, a characteristic of a pure superexchange process is an exponential dependence of charge transfer rate $\left(k_{\mathrm{CT}}\right)$ on the length $(l)$ of the bridge:

$$
k_{\mathrm{CT}}=A \cdot \exp (-\beta l)
$$

where $l$ may correspond to the product of the number of quinoline units multiplied by the length of an individual quinoline unit; $\beta$, attenuation factor. This pattern is not observed (Figure 9). Further evidence against a pure superexchange comes from the positive activation energy of electron transfer (see above). Instead, charge transfer rate dependence on the number of quinoline units (i.e., potential steps in a hopping mechanism) shows a hyperbolic behavior (Figure 9, eq 5) which, according to references, ${ }^{6,22}$ constitutes evidence in favor of a hopping like mechanism. eq 5 represents a simplified dependence of charge transfer rate via a hopping mechanism:

$$
k_{\mathrm{CT}} \sim N^{-\eta}
$$

where $N$ is the number of hops and $\eta$ a phenomenological power parameter. In principle, knowledge of all rates (charge trapping/detrapping, charge hopping, etc.), and of energetic 


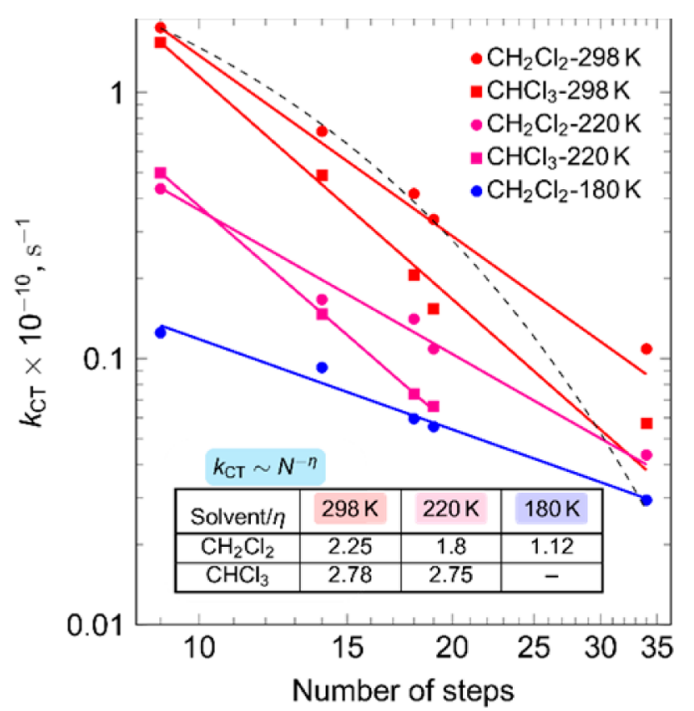

Figure 9. Dependence of the rates of electron transfer between PB and $\mathrm{OPV}$ on the number of quinoline units in the foldamer bridge at different temperatures. The dashed line corresponds to an exponential fit, the solid lines correspond to a hyperbolic fit.

parameters (activation barriers, potentials of oxidation and reduction) might allow modeling of charge transfer dynamics in the system, as was previously described for DNA (Thermally Induced Hopping model). ${ }^{73,75-79}$

According to the random walk theory, which is frequently applied to DNA hole transfer studies, ${ }^{6}$ the phenomenological power parameter $\eta$ in eq 5 equals to (a) 2 in the case of unbiased transfer; (b) $1 \leq \eta \leq 2$ for acceptor direction biased random walk; (c) $\eta>2$ for donor direction biased random walk. Figure 9 shows that $\eta$ is reduced from 2.25 to 1.1 upon reducing temperature from 298 to $180 \mathrm{~K}_{\text {in }} \mathrm{CH}_{2} \mathrm{Cl}_{2}$. This result demonstrates qualitative changes in the electronic properties of the bridge, and consequently on hole transport, with temper ature. Significant reduction of $\eta$ is a result of the fact that longer bridges show smaller observed activation energies (Table 3) of charge separation. At very low temperatures, the rates ratio for long and short bridges becomes less pronounced than at higher temperatures, leading to $\eta$ diminution.

According to Jortner, ${ }^{6}$ it is possible to relate the cumulative rate of hole transport and the rate of individual hop step with number of steps $(N)$ :

$$
k_{\mathrm{CT}} \sim k_{\mathrm{HOP}} N
$$

giving the rate of a single hop $\left(k_{\mathrm{HOP}}\right)$ at $298 \mathrm{~K}$ of $2.5 \times 10^{12} \mathrm{~s}^{-1}$ $(\tau=400 \mathrm{fs})$ in $\mathrm{CH}_{2} \mathrm{Cl}_{2}$ and $1.8 \times 10^{12} \mathrm{~s}^{-1}(\tau=560 \mathrm{fs})$ in $\mathrm{CHCl}_{3}$. The foldamer bridges are rigid helical structures and, therefore, one may wonder whether hole transfer occurs between quinoline units that are directly adjacent in the oligomeric sequence, or between a quinoline and another appropriately oriented in an adjacent turn (above or below) in the helix, but not adjacent in the sequence. In the latter case, the number of steps for the hole to hop through an entire bridge from the $\mathrm{PB}$ to the OPV will be reduced since there are only 3 full turns in OPV $\mathrm{Q}_{2} \mathrm{~PB}$, and 6, 8, and 14 turns in OPV $\mathrm{Q}_{14} \mathrm{~PB}, \mathrm{OPV} \mathrm{Q}_{19} \mathrm{~PB}$ and OPV $\mathrm{Q}_{34} \mathrm{~PB}$, respectively. Never theless, according to the random walk theory, the qualitative description of hole transport will be identical in both scenarios: if holes hop across the helix and skip some quinoline steps, the number of hops is reduced but the rate of single hops is commensurately reduced as well.

OPV $Q_{18}$ PB differs from other triads by the relative orientation of its OPV and PB (Figure 1). This difference does not affect the charge separation rate between $\mathrm{PB}$ and OPV. As shown in Figure 9, values for OPV $Q_{18}$ PB lie on the theoretically generated curves, showing that only distance matters in determining hole transport rate through long triads, in contrast to findings for very short triads. ${ }^{55}$

To account for the above observations, we propose a simplified model based on classical understanding of charge transfer through modular bridges. This model takes into account that through bridge hole transfer is hindered by barriers between quinoline units as well as by an attractive electrostatic interaction between its own positive charge and the negatively charged $\mathrm{PB}^{\bullet-}$. The electrostatic interaction is diminished upon increasing solvent polarity and may also be influenced by the polar nature of the aromatic amide helix backbone, which might generate a macrodipole. For example, the dielectric constant of $\mathrm{CHCl}_{3}$ is smaller than that of $\mathrm{CH}_{2} \mathrm{Cl}_{2}$, leading to a weaker dielectric screening of the charges and thus to a decrease of charge transfer rates, that is in agreement with experiment (Figure 5, 9). In the extreme case of OPV $\mathrm{Q}_{34} \mathrm{~PB}$, the hole never reaches OPV moieties in $\mathrm{CHCl}_{3}$ at temperatures lower than $273 \mathrm{~K}$ (Figure 5), because the rate of hole transfer becomes slower than the rate of charge recombination between $\mathrm{PB}^{\bullet-}$ anion radical and the $\mathrm{Q}^{\bullet+}$ quinoline cation radical (Figure S15a).

The observed reduction of charge separation activation energy upon increasing bridge length is a key for complete understanding of through bridge charge transfer. We must pay attention to the fact that experimentally determined activation energies of charge separation (Table 3) take in account the overall process of charge separation in triads, including through bridge charge transfer and quinoline to excited PB charge injection. The activation energies characterize the overall energy barriers that the charge must overcome between the initial and final states of the charge separation process. For example, charge injection and charge separation for OPV $Q_{9}$ $\mathrm{PB}$ are not distinguishable at room temperature, suggesting that charge injection is rate limiting in this case. The observed reduction of charge separation activation energies with increasing quinoline bridge length, while charge injection activation energies remains constant, implies that charge transport through longer bridges becomes faster at low temperatures. This may be explained by the presence of two mechanisms of charge transfer through the bridge: hopping (a predominant process) and tunneling (a minor process) between units whose respective contributions depend on bridge length. Marcus ${ }^{77}$ demonstrated that nonexponential temperature dependence of electrical conductivity through DNA $^{76}$ could be explained by assuming that there are two mechanisms of charge transfer in long DNA: hopping via localized states and transfer through partly delocalized states. A similar model could explain observed activation energy variations in OPV $Q_{n} P B$ triads. However, an open question remains: why does the hopping mechanism have a higher relative weight than tunneling for shorter triads? One could argue that the Coulombic force between the negative charge on $\mathrm{PB}$ and hole could cause hole localization in shorter triads. With bridge length increase, influence of such forces would be relatively diminished leading to hole delocalization. Yet, in the 
absence of irrefutable evidence of hole delocalization, the question remains open.

In general, it should be understood that as foldamer length increases, the rate of individual hopping steps appears to change. This suggests the coexistence of different mechanisms whose relative contributions would vary as the charge is further away from $\mathrm{PB}^{\bullet-}$. For example, pure hopping between adjacent sites may be mixed with a longer range charge transfer, for example superexchange or a variable length hopping including hopping between consecutive turns of the helical bridge. ${ }^{76,77}$ Deciphering the contributions of these different mechanisms will account for the different $\Delta G$ values for short and long bridges.

In previous work ${ }^{55}$ on OPV $Q_{n}$ PB triads with $n=2,4,5,9$, fast electron transfer was attributed to a superexchange process. We observed that $\mathrm{PB}$ emission was quenched and that the quenching time constant for all studied samples with bridges $n \leq 9$ is smaller than 50 ps. This latter fact is important, as we have now shown that electron transfer from the $\mathrm{Q}_{n}$ bridge to excited PB in short $\mathrm{Q}_{n} \mathrm{~PB}$ dyads $(n \leq 4)$ in $\mathrm{CHCl}_{3}$ or $\mathrm{CH}_{2} \mathrm{Cl}_{2}$ is slower than in triads (see Table 2 ). We thus infer that the initial electron injection from the bridge to $\mathrm{PB}$ does not take place for the shorter triads and that a true superexchange must take place to explain rapid quenching of $\mathrm{PB}$ emission. For longer $Q_{n}$ segments, electron injection from the bridge to $P B$ is faster than overall charge separation, which implies a hopping mechanism. We had previously noted that the rate of electron transfer depending on the length of foldamer bridge is not monotonously changing and has a point of inflection for the triad where $n=5 .^{55}$ Combined with current experimental results, the borderline between pure superexchange and mixed mechanisms is seen to lie in the range $5<n<9$. For OPV $Q_{9}$ $\mathrm{PB}$ at ambient temperature, the growth of $\mathrm{PB}$ anion radical band and the appearance of OPV ground state bleaching occur at the same rate, which, at first sight, suggests that a superexchange mechanism is at play. However, low temperature studies clearly revealed a multistep process implying hopping. Only for this compound do our new conclusions differ from those of our earlier study. For OPV $Q_{n}$ PB triads, a transition from a pure superexchange (delocalized) electron transfer mechanism to a mixed electron transfer through the bridge behavior (localized + delocalized) occurs at $n<9$. The transition from a pure superexchange to what we call a dual mechanism, could be understood in terms of donor-acceptor conjugation in the excited state. This is clearly observed for short foldamers and is absent for longer foldamer based triads, according to experimental observation on electron transfer rates. Direct donor to acceptor charge transfer is thus impossible in longer foldamers and a multistep charge transfer takes over.

Mechanism of Charge Recombination. Studies on OPV $\mathrm{Q}_{n} \mathrm{~PB}$ triads on long time scales, hundreds of microseconds, showed that recombination (OPV GSB band recovers, and $\mathrm{PB}^{\bullet-}$ and $\mathrm{OPV}^{\bullet+}$ bands decay simultaneously) leads to the slow (tens of microseconds depending on concentration) formation of the charge recombined PB triplet state, that slowly relaxes to the ground state. The formation of $\mathrm{PB}$ triplet state during intramolecular CR could be understood in the light of different mechanisms: radical pair (RP) intersystem crossing and spinorbit (SO) intersystem crossing (ISC). ${ }^{80-82}$ The radical pair intersystem crossing mechanism requires the coupled spins of the radical pair in the charge separated state to dephase, leading to the formation of a triplet charge separated state, that evolves to a local charge recombined triplet state (in this case that of $\mathrm{PB})$. In spin-orbit intersystem crossing, while electrons move between orbitals of different symmetry, a change of spin angular momentum is required to fulfill total system angular momentum conservation. ${ }^{81}$ Taking into account the extremely long lifetimes of the CSS state of long triads $(n \geq 14)$, intermolecular interactions may take place due to the diffusion of molecules. This would increase the likelihood that a SO ISC mechanism contributes to the generation of the PB triplet state after $\mathrm{CR}$. The concentration dependence of the CR rate is consistent with this hypothesis. Significant distances between anion and cation radicals and screening effects due to the solvent decrease the probability of spin-spin interaction in long triads and thus lower chance of RP ISC. Meanwhile, the concentration dependence did not show a steep effect, thus we cannot exclude the contribution of other mechanisms. A charge recombination process in dyad $\mathrm{Q}_{8}^{\bullet+} \mathrm{PB}^{\bullet-}$ also ends in $\mathrm{PB}$ triplet state formation. It occurs in the subnanosecond range scale, as for short triads, $n<9$. Charge recombination in OPV $\mathrm{Q}_{\text {PB }} \mathrm{PB}$ also occurs relatively fast. In these cases, intermolecular processes may not play a significant role and intramolecular CR processes must be considered. Other investigations such as time resolved EPR would be needed to differentiate RP ISC and SO ISC. ${ }^{81}$

\section{CONCLUSION}

We investigated time resolved photoinduced charge separation between an OPV electron donor and a PB acceptor through a helically folded oligoquinoline bridge of increasing length (9, $14,18,19,34$ units) in solvents with different polarity, $\mathrm{CHCl}_{3}$ and $\mathrm{CH}_{2} \mathrm{Cl}_{2}$, and at different temperatures. The synthetic availability of these large functional oligomers constitutes an important advance in the field of foldamers. Charge separation was found to occur very fast, in the subnano and nanosecond time scales, even across the longest bridges which span more than $306 \AA$ along the backbone, an achievement that had previously been observed principally with DNA. The general mechanism of charge separation following excitation can be described in four steps: (1) PB electron acceptor photo excitation; (2) electron injection from the HOMO of a quinoline unit of the bridge to the electron acceptor SOMO with a rate of $1.7 \times 10^{10} \mathrm{~s}^{-1}(298 \mathrm{~K})$; (3) hole migration along the helical oligoquinoline bridge from the acceptor to the donor site by a random, reversible hopping between units, with single hop event rate at $298 \mathrm{~K}$ of $2.5 \times 10^{12} \mathrm{~s}^{-1}(\tau=400 \mathrm{fs})$ in $\mathrm{CH}_{2} \mathrm{Cl}_{2}$ and $1.8 \times 10^{12} \mathrm{~s}^{-1}$ ( $\tau=560 \mathrm{fs}$ ) in $\mathrm{CHCl}_{3}$; (4) hole trapping by OPV electron donor finalizing the formation of the charge separated state, which was shown to have an extremely long lifetime of $\tau>80 \mu \mathrm{s}$ in $\mathrm{CH}_{2} \mathrm{Cl}_{2}$ at $15 \mu \mathrm{M}$. These conclusions complement and apparently do not contradict our earlier hypothesis that electron transfer occurred via a superexchange mechanism for very short bridges $(n \leq 5)$; the interpretation for $n=9$ was revised. The charge recombination of long foldamers probably occurs through intermolecular interactions, leading to formation of long lived charged recombined triplet states of $\mathrm{PB}\left(\tau>360 \mu \mathrm{s}\right.$ in $\mathrm{CH}_{2} \mathrm{Cl}_{2}$ at $15 \mu \mathrm{M})$. Variable temperature studies revealed that the activation energy of charge transfer $\Delta G^{\ddagger}$ decreases upon increasing bridge length. The origin of this phenomenon is not yet certain but it could result from the coexistence of two distinct mechanisms of hole transfer along the bridge. Also, whether holes only hop between quinolines adjacent in the sequence or whether they may also directly hop between 
contiguous turns of the helix remains to be elucidated. Progress along these lines is currently being made in our laboratories and will be reported in due course.

Solution studies such as those presented above allow one to decipher complex intramolecular processes. Ultimately, incor poration into devices will require integration in the solid state where numerous intermolecular processes may occur. For example, the observation of long lived charge separated states in solution, a desirable property for applications in photo voltaics, may not be simply extrapolated to the solid state. The successful integration of aromatic foldamers into metalorganic-metal junctions and their electron transport properties in the absence of solvent will be reported elsewhere.

\section{AUTHOR INFORMATION}

\section{Corresponding Authors}

*serguei.denisov@u bordeaux.fr

*i.huc@iecb.u bordeaux.fr

\section{Author Contributions}

${ }^{\#}$ X.L. and N.M. contributed equally to this work.

\section{Notes}

The authors declare no competing financial interest.

\section{ACKNOWLEDGMENTS}

We thank the facilities of IECB for expert assistance in mass spectrometry, and Dr. S. Massip for refining the crystal structure of OPV $\mathrm{QCO}_{2} \mathrm{H}$. This work was supported by an ANR Grant (FOSET project no. ANR 12 BS08 0007 01, postdoctoral fellowships to N. M. and S. D.) and by the European Union under the Erasmus Mundus program (predoctoral fellowship to X. L.).

\section{REFERENCES}

(1) Ritz, T.; Damjanović, A.; Schulten, K. ChemPhysChem 2002, 3, 243-248.

(2) Nelson, N.; Yocum, C. F. Annu. Rev. Plant Biol. 2006, 57, 521565.

(3) Reece, S. Y.; Hodgkiss, J. M.; Stubbe, J.; Nocera, D. G. Philos. Trans. R. Soc., B 2006, 361, 1351-1364.

(4) Weinberg, D. R.; Gagliardi, C. J.; Hull, J. F.; Murphy, C. F.; Kent, C. A.; Westlake, B. C.; Paul, A.; Ess, D. H.; McCafferty, D. G.; Meyer, T. J. Chem. Rev. 2012, 112, 4016-4093.

(5) Reece, S. Y.; Nocera, D. G. Annu. Rev. Biochem. 2015, 78, 673699.

(6) Jortner, J.; Bixon, M.; Langenbacher, T.; Michel Beyerle, M. E. Proc. Natl. Acad. Sci. U. S. A. 1998, 95, 12759-12765.

(7) Friedberg, E. C.; Walker, G. C.; Siede, W. DNA Repair and Mutagenesis; ASM Press, 1995.

(8) Sancar, A.; Lindsey Boltz, L. A.; Ünsal Kaçmaz, K.; Linn, S. Annu. Rev. Biochem. 2004, 73, 39-85.

(9) Rochaix, J. D. Biochim. Biophys. Acta, Bioenerg. 2011, 1807, 375383.

(10) Beckers, E. H. A.; Meskers, S. C. J.; Schenning, A. P. H. J.; Chen, Z.; Würthner, F.; Janssen, R. A. J. J. Phys. Chem. A 2004, 108, 69336937.
(11) Beckers, E. H. A.; Jonkheijm, P.; Schenning, A. P. H. J.; Meskers, S. C. J.; Janssen, R. A. J. ChemPhysChem 2005, 6, 2029-2031.

(12) Kocherzhenko, A. A.; Whaley, K. B.; Sforazzini, G.; Anderson, H. L.; Wykes, M.; Beljonne, D.; Grozema, F. C.; Siebbeles, L. D. A. J. Phys. Chem. C 2012, 116, 25213-25225.

(13) Prins, P.; Grozema, F. C.; Siebbeles, L. D. A. J. Phys. Chem. B 2006, 110, 14659-14666.

(14) Wenger, O. S. Chem. Soc. Rev. 2011, 40, 3538-3550.

(15) Scott, A. M.; Miura, T.; Ricks, A. B.; Dance, Z. E. X.; Giacobbe, E. M.; Colvin, M. T.; Wasielewski, M. R. J. Am. Chem. Soc. 2009, 131, 17655-17666.

(16) Gilbert, M.; Albinsson, B. Chem. Soc. Rev. 2014, 44, 845-862.

(17) Weiss, E. A.; Wasielewski, M. R.; Ratner, M. A. Top. Curr. Chem. 2005, 257, 103-133.

(18) Scott, A. M.; Wasielewski, M. R. J. Am. Chem. Soc. 2011, 133, 3005-3013.

(19) Scott, A. M.; Ricks, A. B.; Colvin, M. T.; Wasielewski, M. R. Angew. Chem., Int. Ed. 2010, 49, 2904-2908.

(20) Natali, M.; Campagna, S.; Scandola, F. Chem. Soc. Rev. 2014, 43, 4005-4018.

(21) Waldvogel, S. R.; Mück Lichtenfeld, C. Angew. Chem., Int. Ed. 2001, 40, 4295-4297.

(22) May, V.; Kühn, O. Charge and Energy Transfer Dynamics in Molecular Systems; Wiley VCH, 2004.

(23) Giese, B. Bioorg. Med. Chem. 2006, 14, 6139-6143.

(24) Wagenknecht, H. A. Charge Transfer in DNA: From Mechanism to Application; Wiley, 2005.

(25) Jones, G., II; Zhou, X.; Vullev, V. I. Photochem. Photobiol. Sci. 2003, 2, 1080-1087.

(26) Cordes, M.; Giese, B. Chem. Soc. Rev. 2009, 38, 892-901.

(27) Gao, J.; Müller, P.; Wang, M.; Eckhardt, S.; Lauz, M.; Fromm, K. M.; Giese, B. Angew. Chem., Int. Ed. 2011, 50, 1926-1930.

(28) Shah, A.; Adhikari, B.; Martic, S.; Munir, A.; Shahzad, S.; Ahmad, K.; Kraatz, H. Chem. Soc. Rev. 2015, 44, 1015-1027.

(29) Arikuma, Y.; Nakayama, H.; Morita, T.; Kimura, S. Langmuir 2011, 27, 1530-1535.

(30) Garo, F.; Häner, R. Angew. Chem., Int. Ed. 2012, 51, 916-919.

(31) Dutta, P. K.; Varghese, R.; Nangreave, J.; Lin, S.; Yan, H.; Liu, Y. J. Am. Chem. Soc. 2011, 133, 11985-11993.

(32) Winiger, C. B.; Langenegger, S. M.; Calzaferri, G.; Häner, R. Angew. Chem., Int. Ed. 2015, 54, 3643-3647.

(33) Renaud, N.; Berlin, Y. A.; Lewis, F. D.; Ratner, M. A. J. Am. Chem. Soc. 2013, 135, 3953-3963.

(34) Xiang, L.; Palma, J. L.; Bruot, C.; Mujica, V.; Ratner, M. A.; Tao, N. Nat. Chem. 2015, 7, 221-226.

(35) Slinker, J. D.; Muren, N. B.; Renfrew, S. E.; Barton, J. K. Nat. Chem. 2011, 3, 228-233.

(36) Fukui, K.; Tanaka, K. Angew. Chem., Int. Ed. 1998, 37, 158-161.

(37) Berlin, Y. A.; Burin, A. L.; Ratner, M. A. Superlattices Microstruct. 2000, 28, 241-252.

(38) Takada, T.; Kawai, K.; Tojo, S.; Majima, T. Tetrahedron Lett. 2003, 44, 3851-3854.

(39) Lewis, F. D.; Zhang, L.; Zuo, X. J. Am. Chem. Soc. 2005, 127, 10002-10003.

(40) Manetto, A.; Breeger, S.; Chatgilialoglu, C.; Carell, T. Angew. Chem., Int. Ed. 2006, 45, 318-321.

(41) Takada, T.; Kawai, K.; Fujitsuka, M.; Majima, T. Proc. Natl. Acad. Sci. U. S. A. 2004, 101, 14002-14006.

(42) Son, M.; Fimmel, B.; Dehm, V.; Würthner, F.; Kim, D. ChemPhysChem 2015, 16, 1757-1767.

(43) Winiger, C. B.; Li, S.; Kumar, G. R.; Langenegger, S. M.; Häner, R. Angew. Chem., Int. Ed. 2014, 53, 13609-13613.

(44) Fimmel, B.; Son, M.; Sung, Y. M.; Grüne, M.; Engels, B.; Kim, D.; Würthner, F. Chem. Eur. J. 2015, 21, 615-630.

(45) Marcos Ramos, A.; Meskers, S. C. J.; Beckers, E. H. A.; Prince, R. B.; Brunsveld, L.; Janssen, R. A. J. J. Am. Chem. Soc. 2004, 126, 9630-9644.

(46) Zeidan, T. A.; Wang, Q.; Fiebig, T.; Lewis, F. D. J. Am. Chem. Soc. 2007, 129, 9848-9849. 
(47) Zhang, D. W.; Zhao, X.; Hou, J. L.; Li, Z. T. Chem. Rev. 2012, 112, 5271-5316.

(48) Huc, I. Eur. J. Org. Chem. 2004, 2004, 17-29.

(49) Sebaoun, L.; Maurizot, V.; Granier, T.; Kauffmann, B.; Huc, I. J. Am. Chem. Soc. 2014, 136, 2168-2174.

(50) Ferrand, Y.; Kendhale, A. M.; Garric, J.; Kauffmann, B.; Huc, I. Angew. Chem., Int. Ed. 2010, 49, 1778-1781.

(51) Gan, Q.; Bao, C.; Kauffmann, B.; Grélard, A.; Xiang, J.; Liu, S.; Huc, I.; Jiang, H. Angew. Chem., Int. Ed. 2008, 47, 1715-1718.

(52) Delsuc, N.; Massip, S.; Léger, J. M.; Kauffmann, B.; Huc, I. J. Am. Chem. Soc. 2011, 133, 3165-3172.

(53) Delsuc, N.; Leger, J. M.; Massip, S.; Huc, I. Angew. Chem., Int. Ed. 2007, 46, 214-217.

(54) Chandramouli, N.; Ferrand, Y.; Lautrette, G.; Kauffmann, B.; Mackereth, C. D.; Laguerre, M.; Dubreuil, D.; Huc, I. Nat. Chem. 2015, 7, 334-341.

(55) Wolffs, M.; Delsuc, N.; Veldman, D.; Anh, N. V.; Williams, R. M.; Meskers, S. C. J.; Janssen, R. A. J.; Huc, I.; Schenning, A. P. H. J. J. Am. Chem. Soc. 2009, 131, 4819-4829.

(56) Jiang, H.; Léger, J. M.; Huc, I. J. Am. Chem. Soc. 2003, 125, 3448-3449.

(57) Delsuc, N.; Kawanami, T.; Lefeuvre, J.; Shundo, A.; Ihara, H.; Takafuji, M.; Huc, I. ChemPhysChem 2008, 9, 1882-1890.

(58) Benniston, A. C.; Harriman, A. Chem. Soc. Rev. 2006, 35, 169179.

(59) Qi, T.; Deschrijver, T.; Huc, I. Nat. Protoc. 2013, 8, 693-708.

(60) Li, X.; Qi, T.; Srinivas, K.; Massip, S.; Maurizot, V.; Huc, I. Org.

Lett. 2016, 18, 1044-1047.

(61) Che, Y.; Datar, A.; Balakrishnan, K.; Zang, L. J. Am. Chem. Soc. 2007, 129, 7234-7235.

(62) Wicklein, A.; Lang, A.; Muth, M.; Thelakkat, M. J. Am. Chem. Soc. 2009, 131, 14442-14453.

(63) Smallwood, I. M. Handbook of Organic Solvent Properties; Butterworth Heinemann: Oxford, 1996.

(64) Mccarthy, W. J.; Dunlap, K. L. Talanta 1970, 17, 305-317.

(65) Sung, J.; Kim, P.; Fimmel, B.; Würthner, F.; Kim, D. Nat. Commun. 2015, 6, 8646.

(66) Chen, Z.; Stepanenko, V.; Dehm, V.; Prins, P.; Siebbeles, L. D. A.; Seibt, J.; Marquetand, P.; Engel, V.; Würthner, F. Chem. Eur. J. 2007, 13, 436-449.

(67) Hippius, C.; van Stokkum, I. H. M.; Zangrando, E.; Williams, R. M.; Würthner, F. J. Phys. Chem. C 2007, 111, 13988-13996.

(68) Nicolaescu, A. R.; Wiest, O.; Kamat, P. V. J. Phys. Chem. A 2003, $107,427-433$.

(69) Ventura, B.; Langhals, H.; Bock, B.; Flamigni, L. Chem. Commun. 2012, 48, 4226-4228.

(70) Davis, W. B.; Ratner, M. A.; Wasielewski, M. R. J. Am. Chem. Soc. 2001, 123, 7877.

(71) Weiss, E. A.; Tauber, M. J.; Kelley, R. F.; Ahrens, M. J.; Ratner, M. A.; Wasielewski, M. R. J. Am. Chem. Soc. 2005, 127, 11842-11850.

(72) Wasielewski, M. R. J. Org. Chem. 2006, 71, 5051-5066.

(73) Goldsmith, R. H.; DeLeon, O.; Wilson, T. M.; Finkelstein Shapiro, D.; Ratner, M. A.; Wasielewski, M. R. J. Phys. Chem. A 2008, 112, 4410-4414.

(74) Marcus, R. A.; Sutin, N. Biochim. Biophys. Acta, Rev. Bioenerg. 1985, 811, 265-322.

(75) Bixon, M.; Jortner, J. J. Am. Chem. Soc. 2001, 123, 1255612567.

(76) Yu, Z. G.; Song, X. Phys. Rev. Lett. 2001, 86, 6018-6021.

(77) Renger, T.; Marcus, R. A. J. Phys. Chem. A 2003, 107, 84048419.

(78) Meggers, E.; Michel Beyerle, M. E.; Giese, B. J. Am. Chem. Soc. 1998, 120, 12950-12955.

(79) Giese, B.; Wessely, S.; Spormann, M.; Lindemann, U.; Meggers, E.; Michel Beyerle, M. E. Angew. Chem., Int. Ed. 1999, 38, 996-998.

(80) Ahrens, M. J.; Kelley, R. F.; Dance, Z. E. X.; Wasielewski, M. R. Phys. Chem. Chem. Phys. 2007, 9, 1469-1478.

(81) Colvin, M. T.; Ricks, A. B.; Scott, A. M.; Co, D. T.; Wasielewski, M. R. J. Phys. Chem. A 2012, 116, 1923-1930.
(82) Horwitz, N. E.; Phelan, B. T.; Nelson, J. N.; Krzyaniak, M. D.; Wasielewski, M. R. J. Phys. Chem. A 2016, 13, 2841-2853.

(83) Indeed, the overall electron dynamics consist of multiple steps, and as a result, $\mathrm{OPV}^{\bullet+}$ concentration growth would be better described by a kinetic model including the successive individual steps, which cannot be reduced to a first order process. 